\title{
Effect of Red Light Treatment of Seedlings of Pepper, Pumpkin, and Tomato on the Occurrence of Phytophthora Damping-off
}

\author{
S.Z. Islam and M. Babadoost \\ Department of Crop Sciences, University of Illinois, Urbana, IL 61801
}

Y. Honda

Faculty of Life and Environmental Science, Shimane University, Matsue, Japan

Additional index words. Phytophthora capsici, seedling damping-off, red light, induced resistance

\begin{abstract}
A study was conducted in the greenhouse to investigate the effects of red light $(600-700 \mathrm{~nm})$ on the subsequent occurrence of seedling infection of bell pepper, pumpkin, and tomato caused by Phytophthora capsici. Three- or 4-week-old seedlings were inoculated with zoospores or transplanted into pots filled with artificially infested soil mix. Red light treatment of seedlings reduced Phytophthora damping-off by up to $79 \%$. Only $21 \%$ to $36 \%$ of red light-treated seedlings became infected, whereas $78 \%$ to $100 \%$ of the control seedlings, grown either in natural daylight (NDL) or under white light (WL), became infected and died. The height, and fresh and dry weight of seedlings treated with red light were significantly higher than those grown under NDL or WL.
\end{abstract}

Phytophthora blight, caused by Phytophthora capsici Leonian, has become one of the most serious threats to production of cucurbit crops, peppers, and tomatoes nationwide (Babadoost, 2000a, 2000b; Matheron and Matejka, 1995; Roberts et al., 2000). Recently, the incidence of damping-off, foliar blight, and fruit rot on melons, peppers, pumpkins, squashes, and watermelon caused by $P$. capsici has dramatically increased in Illinois (Babadoost, 2000a, 2000b). In the past 3 years, Phytophthora blight has been epidemic in processing pumpkin and bell pepper fields in Illinois and caused yield losses up to $100 \%$ (Babadoost, 2000b). Infection of the plants in the field may occur at any time during the growing season. Early infections cause seedling damping-off, and later infections cause foliar blight, stem lesions, vine rot, fruit rot, and root and crown rot (Lee et al., 2001; Matheron and Matejka, 1995). Practices such as planting on raised beds, management of field moisture, straw mulching, planting tolerant cultivars, and application of some fungicides may reduce severity of Phytophthora diseases of vegetables. No single method is available, however, to provide adequate control of $P$. capsici on vegetables (Hwang and Kim, 1995). Host resistance, if available, would be an ideal biological defense against $P$. capsici. No pumpkin or chili pepper cultivar with measurable resistance to Phytophthora blight is available. Resistance to Phytophthora blight in a few cultivars of bell pepper has been reported (Boucher and Ashley, 2000), but they

Received for publication 18 July 2001. Accepted for publication 17 Jan. 2002. may not be commercially acceptable in all pepper-growing areas.

In nature, plants are exposed to light of different wavelengths, from ultraviolet (UV) to far-red regions. Light of certain wavelengths (i.e., 290-320 nm) may affect certain hostpathogen interactions (Honda, 2000; Kumagai, 1988; Tan, 1978). Light was reported as one of the important factors affecting disease development by inactivating toxins of pathogens in certain plant/pathogen interactions (Akimitsu et al., 1988; Kohmoto et al., 1989). There are several reports of phytoalexins produced by host-parasite interactions in plant tissue that protect the host plant from the pathogen. Ultraviolet irradiation $(253 \mathrm{~nm})$ of soybean plants induced resistance against $P$ hytophthora sojae by inducing the production of the phytoalexin hydroxyphaseollin (Bridge and Klarman, 1973). Accumulation of phytoalexins in plants receiving short-wave UV radiation $(254 \mathrm{~nm})$ was also reported by several investigators (Hadwiger and Schwochaw, 1971; Kato et al.,

Recently, several investigators reported that red light treatment induces disease resistance in plants (Islam et al., 1998a, 1998b, 1999; Rahman et al., 2001). Light of long wavelengths (red region, 600-700 nm) induced resistance in broadbean (Vicia faba L.) against Botrytis cinerea (Islam et al., 1998b). They also reported that irradiation of broadbean leaflets with red light resulted in production of an antifungal substance (phytoalexin) in leaf tissue. Red light was also reported to suppress the lesion development of $P$. capsici on detached leaves of eggplant, pepper, pumpkin, and watermelon (Umezu et al., 1999). Induced resistance in plants by red light against Alter1994; Kodama et al., 1992). naria tennuissima has also been reported recently (Rahman et al., 2001). However, most of the reports on red light-induced resistance against plant pathogens are from studies carried out on detached leaves. The objective of this study was to investigate whether treatment of seedlings with red light can protect the plants from damping-off caused by $P$. capsici.

\section{Material and Methods}

Phytophthora capsici was isolated from an infected pumpkin seedling (Cucurbita moschata L.) collected from Pekin, Ill., and the culture was maintained on lima bean agar (LBA; Difco Lab., Detroit) slants. Sporangial suspensions were prepared from 5- to 6-dayold culture plates of $P$. capsici grown on LBA at $24{ }^{\circ} \mathrm{C}$ under continuous white fluorescent light. Ten milliliters of sterilized-distilled water (SDW) were added to each plate and the sporangia were dislodged using a soft brush. The suspension was then incubated at $20^{\circ} \mathrm{C}$ for 1 $\mathrm{h}$ to allow the sporangia to release their zoospores. Zoospores were separated from the empty sporangia by passing the suspension through a four-layered facial tissue (Kleenex). The concentration of zoospores was adjusted to $20 \times 10^{4}$ zoospores $/ \mathrm{mL}$ water using a hemacytometer (no. 3120, Hausser Scientific Co., Horsham, Pa.).

Inoculum for artificial soil infestation was prepared by growing $P$. capsici on oatmealV8-juice broth (V8JB) substrate in 1-L conical flasks. The substrate, consisting of $200 \mathrm{~g}$ oatmeal and $120 \mathrm{~mL} \mathrm{V8-juice} \mathrm{broth} \mathrm{per} \mathrm{liter,}$ was autoclaved for $30 \mathrm{~min}$ and inoculated with mycelial plugs, $7 \mathrm{~mm}$ in diameter, taken from the margin of a young colony of $P$. capsici grown on LBA. The flasks were then incubated at $24{ }^{\circ} \mathrm{C}$ in darkness. After 6 weeks, the colonized oatmeal was added to steamed soil mix (1 soil : 1 sand : 1 peat) and mixed thoroughly. The inoculum potential of the soil mix was 600 colony forming units (cfu) per gram of soil, which was determined by the dilution-plate-count method.

Seeds of bell pepper (Capsicum annum L.; Hybrid SPP 6112, Sakata Co., Morgan Hill, Calif.), pumpkin (cv. Dickinson), and tomato (Lycopersicon esculentum Mill.; Hybrid XTM 6217 , Sakata Co.) were sown in 10-cm-diameter plastic pots (one seed per pot) containing steamed soil mix and were grown on a greenhouse bench under continuous red light irradiation $(600-700 \mathrm{~nm})$ from fluorescent tubes (FL20S·R-F, National Co., Japan). The fluorescent tubes provided red light with an intensity of $287 \mu \mathrm{W} \cdot \mathrm{cm}^{-2}$, which was a supplement to natural daylight. Control seedlings were kept under continuous white light (WL; FL20SS·D/18, Mitsubishi, Tokyo; 380-740 $\mathrm{nm} ; 473 \mu \mathrm{W} \cdot \mathrm{cm}^{-2}$ ) or under natural daylight (NDL) in the same greenhouse. Three- or 4week-old seedlings were transferred from red light to NDL and inoculation was accomplished by adding the suspension of motile zoospores over the surface of the soil in each pot $(5 \mathrm{~mL} / \mathrm{seedling} / \mathrm{pot})$. Control seedlings either grown in WL or NDL were also inoculated using the same procedure. An additional 
set of control seedlings were inoculated with SDW only. Seedlings were watered before inoculation to keep the soil wet. After inoculation, the pots were placed in plastic trays containing water that kept the soil moist for at least $12 \mathrm{~h}$. The seedlings were then placed on a greenhouse bench, in a completely randomized design, and watered twice daily. Pumpkin and tomato seedlings were also inoculated by transplanting the seedlings into artificially infested soils in pots. Each pot contained one seedling and 14 pots were used for each treatment. Beginning the fourth day after inoculation, seedlings were evaluated for dampingoff symptoms every day for 15 successive days. The seedlings were also evaluated on the 20th day after inoculation. Height, and fresh and dry weights of seedlings were also measured. Dry weight was determined after drying the seedlings at $70{ }^{\circ} \mathrm{C}$ for $24 \mathrm{~h}$. Each experiment was repeated two or three times. Since the results of the experiments were not significantly different from each other, data from one experiment are presented. Data were analyzed using analysis of variance procedures (SAS Institute, Cary, N.C.).

\section{Results}

Pepper. Symptoms of Phytophthora infection began to appear in red light-treated pepper seedlings $12 \mathrm{~d}$ after zoospore inoculation, and $36 \%$ of seedlings became infected and died (Fig. 1). In contrast, symptoms on control seedlings (grown under WL or NDL) first appeared $5 \mathrm{~d}$ after inoculation and within $8 \mathrm{~d}$ of inoculation, $100 \%$ of the seedlings were infected, stem-girdled, and died.

Pumpkin. In the zoospore-inoculated experiment, seedlings treated with red light showed symptoms $12 \mathrm{~d}$ after inoculation. Only $21 \%$ of the seedlings became infected (Fig. 2). In comparison, control seedlings grown under either WL or NDL became symptomatic $5 \mathrm{~d}$ after inoculation and within $15 \mathrm{~d}$ after inoculation, $78 \%$ of seedlings were infected and died. In the infested soil experiment, $28 \%$ of red light-treated and $78 \%$ of control seedlings grown under NDL became infected and died (Fig. 3).

Tomato. In red light-treated tomato seedlings, symptoms started $4 \mathrm{~d}$ after zoospore inoculation, and $28 \%$ of the seedlings were infected and died $15 \mathrm{~d}$ after inoculation (Fig. 4). In contrast, symptoms on control seedlings started $4 \mathrm{~d}$ after inoculation and within $7 \mathrm{~d}$ $100 \%$ of the seedlings became infected, stemgirdled, and died. In the infested soil experiment, only $21 \%$ of red light-treated transplants were found infected and developed symptoms, while $80 \%$ of the control transplants grown under NDL became infected and died $15 \mathrm{~d}$ after inoculation (Fig. 5).

In all of the red light treatments, no more seedling damping-off occurred $15 \mathrm{~d}$ after inoculation of plants.

The height, and fresh and dry weights of red light-treated seedlings were significantly higher than those of seedlings grown under WL or NDL (Table 1). The average height of red light-treated seedlings of pepper, pump-

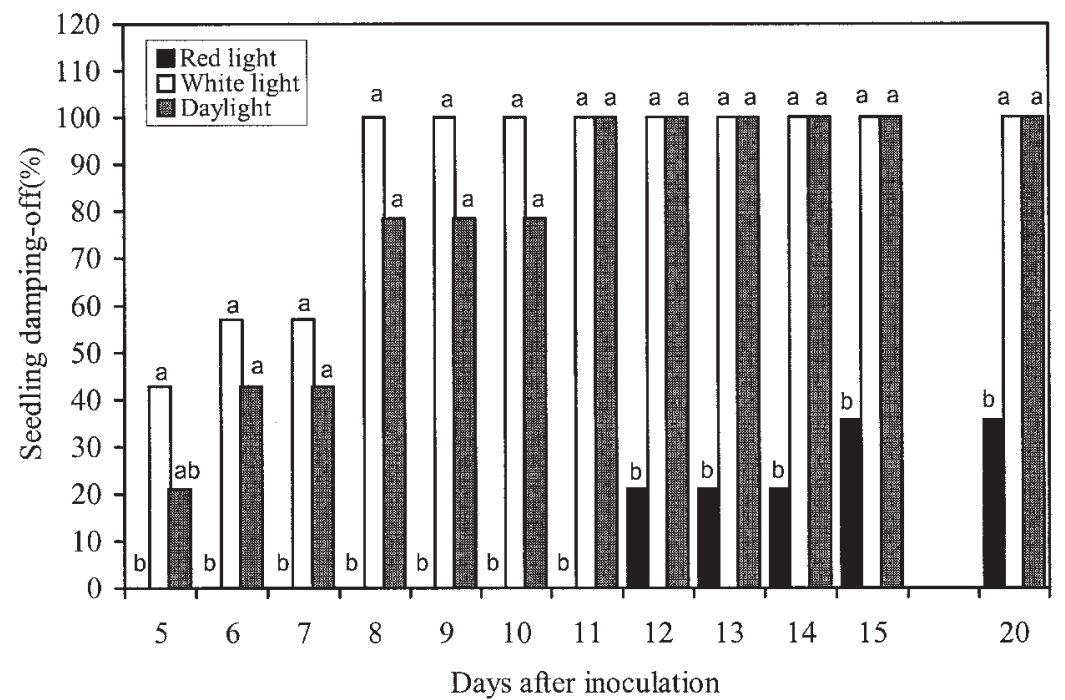

Fig. 1. Effect of light treatment on the occurrence of damping-off in 4-week-old pepper seedlings inoculated with Phytophthora capsici zoospores. Within each day, the columns with a letter in common are not significantly different from each other $(P=0.05$, Fisher's Protected LSD).

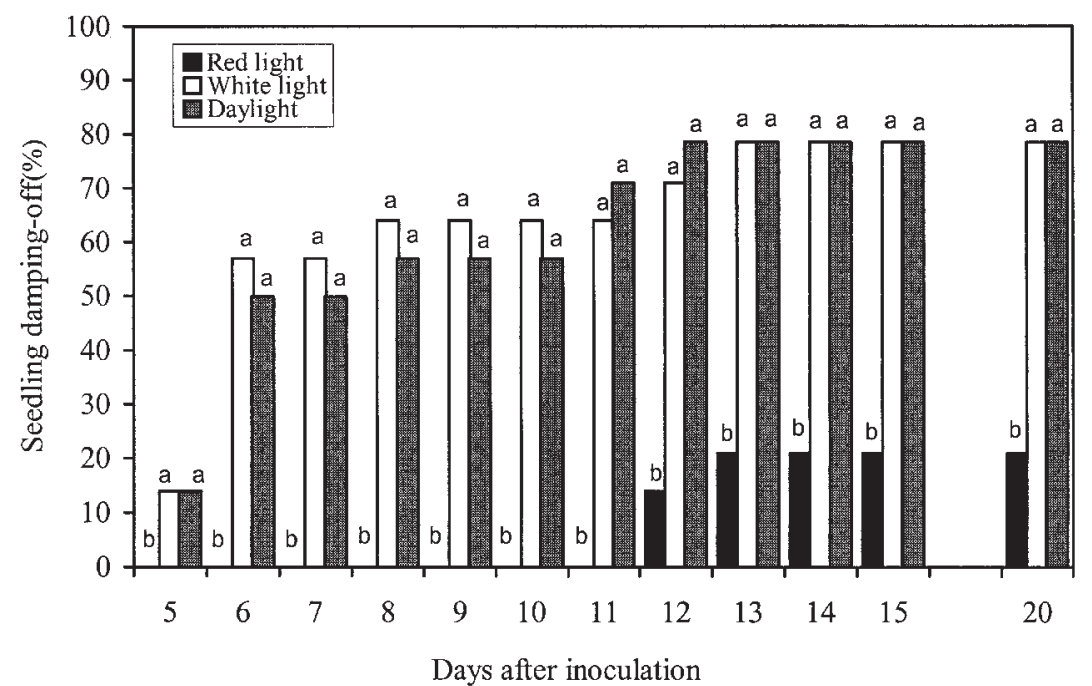

Fig. 2. Effect of light treatment on the occurrence of damping-off in 3-week-old pumpkin seedlings inoculated with Phytophthora capsici zoospores. Within each day, the columns with a letter in common are not significantly different from each other $(P=0.05$, Fisher's Protected LSD).

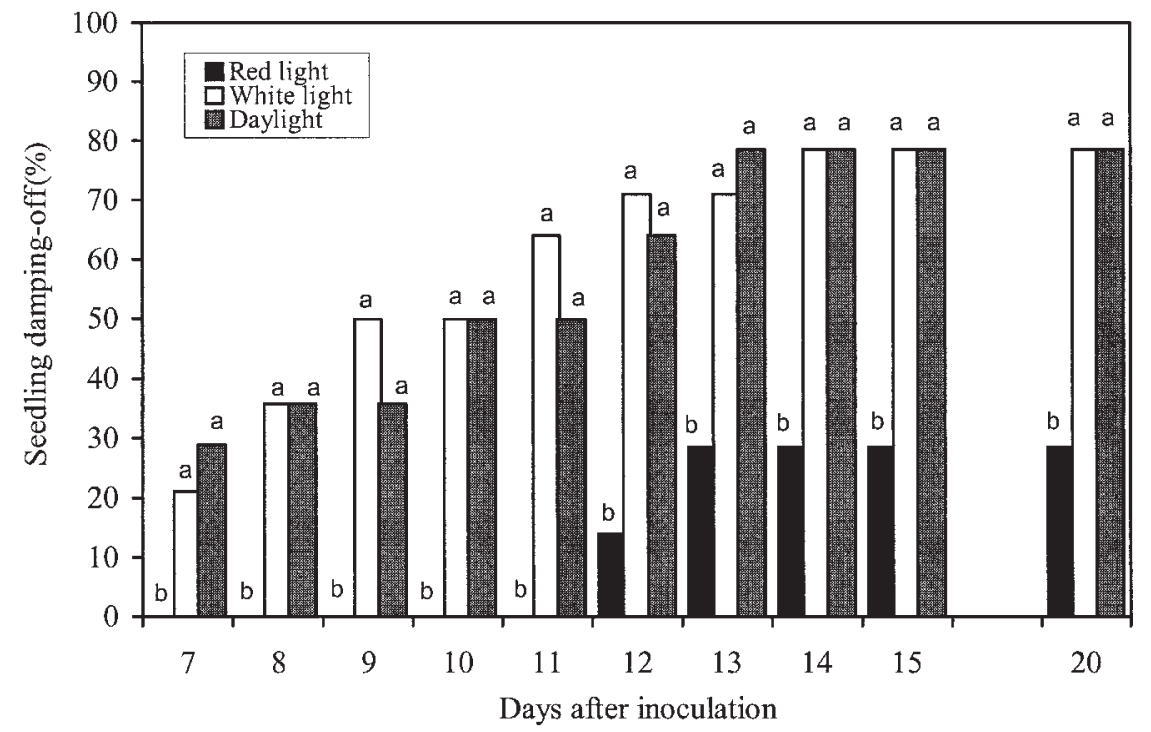

Fig. 3. Effect of light treatment on the occurrence of damping-off in 3-week-old pumpkin seedlings transplanted into the soil infested with Phytophthora capsici. Within each day, the columns with a letter in common are not significantly different from each other $(P=0.05$, Fisher's Protected LSD). 
kin, and tomato were $36.1,33.0$, and $37.6 \mathrm{~cm}$, respectively; whereas the average values were $26.4,25.1$, and $26.7 \mathrm{~cm}$ for seedlings grown under NDL. The average fresh weight of red light-treated seedlings of pepper, pumpkin, and tomato was 9.8, 25.7, and $10.1 \mathrm{~g}$, respectively; while the average fresh weight of seedlings of pepper, pumpkin, and tomato grown under NDL was 5.8, 19.6, and $6.4 \mathrm{~g}$, respectively. The average dry weight of red lighttreated seedlings of pepper, pumpkin, and tomato was $1.5,3.0$, and $1.7 \mathrm{~g}$, respectively, compared to $0.82,1.9$, and $0.87 \mathrm{~g}$, respectively, for NDL. There was no significant difference in height, and fresh and dry weight of seedlings grown under NDL or WL.

\section{Discussion}

Red light treatment of seedlings in greenhouse trials significantly reduced the subsequent occurrence of Phytophthora dampingoff in pepper, pumpkin, and tomato seedlings compared with plants grown under NDL or WL. The results indicate that the red light treatment induces resistance in seedlings against $P$. capsici. These findings agree with the report by Umezu et al. (1999) in which red light treatment induced resistance in detached leaves of pepper, pumpkin, and eggplant against P. capsici.

Seedlings irradiated by white light did not show any disease suppression and there was no significant difference in occurrence of seedling damping-off between the plants grown under WL and NDL. The light intensity of the red light region of a daylight-type white fluorescent tube was measured using a BP-60 filter as described by Islam et al. (1998b); the resulting light intensity was $74 \mu \mathrm{W} \cdot \mathrm{cm}^{-2}$. In this experiment, the intensity of red light provided by the red light fluorescent tubes used for irradiation of seedlings was $287 \mu \mathrm{W} \cdot \mathrm{cm}^{-2}$, indicating that the intensity of red light might be an important factor in inducing resistance in plants. However, further investigations are needed to evaluate the effects of time and period of irradiation and the intensity of red light in inducing resistance in plants. In our study, the seedlings were irradiated continuously by red light from fluorescent tubes. About one-fourth of the sunlight reaching the earth's surface is red light (Honda et al., 1977). So, the supplemented red light from fluorescent tubes during daytime may not be very important and irradiated red light during the night may contribute to inducing resistance against $P$. capsici.

Among the light components, red light (600-700 $\mathrm{nm}$ ) has been reported to be the most effective wavelength region for photosynthesis in green plants (Thomas et al., 1973). However, we don't know the mechanism of induction of resistance by red light treatment in plants against $P$. capsici. Red light irradiation may induce the production of anti-fungal substance(s) in plants. It has been reported that irradiation of broadbean leaves by red light induced the accumulation of an antifungal substance in leaf tissue. This substance prohibited germination of spores of several fun-

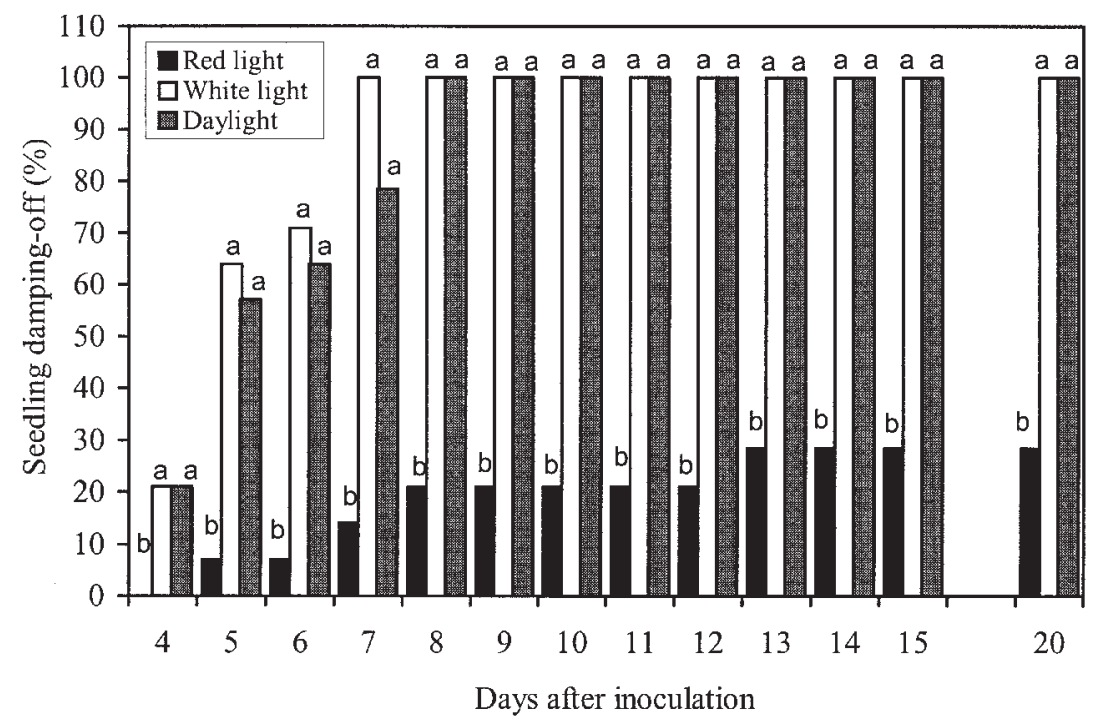

Fig. 4. Effect of light treatment on the occurrence of damping-off in 4-week-old tomato seedlings inoculated with Phytophthora capsici zoospores. Within each day, the columns with a letter in common are not significantly different from each other ( $P=0.05$, Fisher's Protected LSD).

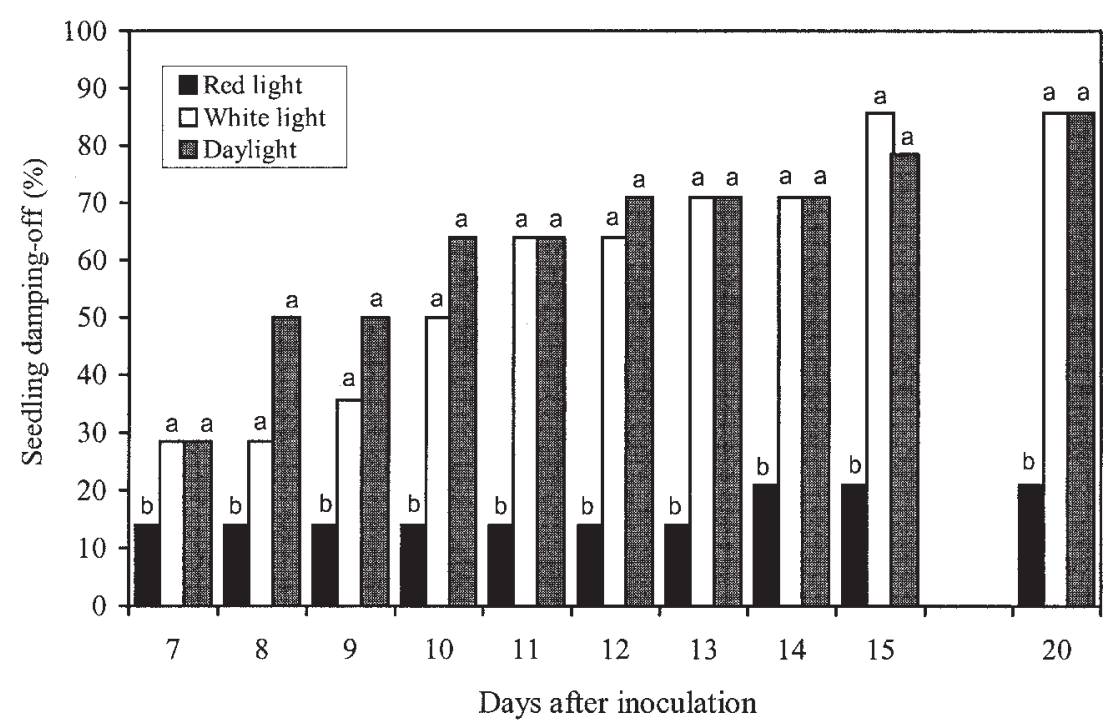

Fig. 5. Effect of light treatment on the occurrence of damping-off in 4-week-old tomato seedlings transplanted into the soil infested with Phytophthora capsici. Within each day, the columns with a letter in common are not significantly different from each other $(P=0.05$, Fisher's Protected LSD $)$.

Table 1. Effect of light treatment on height and fresh and dry weight of vegetable seedlings.

\begin{tabular}{|c|c|c|c|c|c|c|c|c|c|c|c|c|}
\hline \multirow[b]{2}{*}{ Vegetable $^{z}$} & \multicolumn{4}{|c|}{ Height $(\mathrm{cm})$} & \multicolumn{4}{|c|}{ Fresh weight (g) } & \multicolumn{4}{|c|}{ Dry weight (g) } \\
\hline & $\begin{array}{l}\text { Red } \\
\text { light }\end{array}$ & $\begin{array}{l}\text { White } \\
\text { light }\end{array}$ & $\begin{array}{l}\text { Day } \\
\text { light }\end{array}$ & $\begin{array}{c}\text { LSD } \\
(0.05)\end{array}$ & $\begin{array}{l}\text { Red } \\
\text { light }\end{array}$ & $\begin{array}{l}\text { White } \\
\text { light }\end{array}$ & $\begin{array}{l}\text { Day } \\
\text { light }\end{array}$ & $\begin{array}{c}\text { LSD } \\
(0.05)\end{array}$ & $\begin{array}{l}\text { Red } \\
\text { light }\end{array}$ & $\begin{array}{c}\text { White } \\
\text { light }\end{array}$ & $\begin{array}{l}\text { Day } \\
\text { light }\end{array}$ & $\begin{array}{c}\text { LSD } \\
(0.05)\end{array}$ \\
\hline Pepper & 36.1 & 26.9 & 26.4 & 1.70 & 9.8 & 6.0 & 5.8 & 0.46 & 1.5 & 0.79 & 0.82 & 0.23 \\
\hline Pumpkin & 33.0 & 25.4 & 25.1 & 1.26 & 25.7 & 20.0 & 19.6 & 1.97 & 3.0 & 1.8 & 1.9 & 0.18 \\
\hline Tomato & 37.6 & 26.9 & 26.7 & 1.50 & 10.1 & 6.7 & 6.4 & 0.46 & 1.7 & 0.83 & 0.87 & 0.19 \\
\hline
\end{tabular}

${ }^{\mathrm{z}}$ Height, and fresh and dry weights were determined 6 weeks (pepper and tomato) and 4 weeks (pumpkin) after seedling emergence. Each value represents the average of 12 plants.

gal pathogens, including soilborne fungi (Islam et al., 1999). Antifungal substances also have been detected in plants in response to UV light irradiation (Bridge and Klarman, 1973; Hadwiger and Schwochaw 1971; Kato et al., 1994; Kodama et al., 1992).

In the experiments conducted, $78 \%$ to $100 \%$ of plants grown under either WL or NDL became infected with $P$. capsici and died. On the other hand, only $21 \%$ to $36 \%$ of the red light-treated plants became infected, with the remaining plants continuing to grow well. This indicates that infection of pepper, pumpkin, and tomato plants with $P$. capsici in the fields may be reduced by red light treatment of the seedlings prior to transplanting.

In this study, seedlings were inoculated either by growing the plants in infested soil or 
by adding a zoospore suspension onto the crown section of the seedlings. Both methods appeared to be reliable with respect to inoculating the plants and evaluating the effect of the red light treatment. The zoospore-inoculation method, however, was simpler and faster than the soil-infestation method. Thus, the zoospores can be used as a rapid and reliable method for evaluation of the effectiveness of the red light treatment for reducing seedling infection with $P$. capsici. However, final evaluation of the red light-induced resistance must be carried out in the field soil highly infested with $P$. capsici under conditions conducive for development of Phytophthora dampingoff.

In this study, 3- to 4-week-old seedlings were inoculated either by transplanting into infested soil or with a zoospore suspension. Within 2 weeks of inoculation, $78 \%$ to $100 \%$ of pepper, pumpkin, and tomato plants grown under WL or NDL became infected with $P$. capsici and died, indicating that these plants, and perhaps other hosts of $P$. capsici as well, are susceptible to $P$. capsici during early growth stages. This is similar to the finding by Roberts et al. (2000), who concluded that 6- to 8-weekold tomato plants were susceptible to $P$. capsici, with up to $100 \%$ of the plants becoming infected and dying. As a result, the effectiveness of a red light treatment on preventing infection with $P$. capsici can be evaluated in young plants.

Red light treatment promoted seedling growth, significantly increasing height, and fresh and dry weight of plants, compared with those grown under either WL or NDL. The dry weight of red light-treated seedlings was almost twice that of plants grown under WL or NDL. Such rapid growth may be a significant factor in reducing susceptibility of plants to $P$. capsici, as well as for early crop production.

\section{Literature Cited}

Akimitsu, K., T. Shikada, H. Otani, M. Kodama, H. Tabira, and K. Kohmoto. 1994. Light suppresses the action of the host-specific ACR-toxin on citrus leaves. J. Fac. Agr., Tottori Univ. 30:17-27.

Babadoost, M. 2000a. Outbreak of Phytophthora foliar blight and fruit rot in processing pumpkin fields in Illinois. Plant Dis. 84:1345.

Babadoost, M. 2000b. Incidence and impact of Phytophthora diseases on Illinois vegetables. Proc. ISHS Orchard and SIU Hort. Day 2000:22-25.

Boucher, T.J. and R.A. Ashley. 2000. Northeast pepper, integrated pest management (IPM) manual. Coop. Ext. Syst., Univ. of Connecticut, Storrs.

Bridge, M.A. and W.L. Klarman. 1973. Soybean phytoalexin, hydroxyphaseollin, induced by ultraviolet irradiation. Phytopathology 63:606608.

Hadwiger, L.A. and M.E. Schwochau. 1971. Ultraviolet light-induced formation of pisatin and phenylalanine ammonia lyase. Plant Physiol. 47:588-590.

Honda, Y. 2000. UV-B radiation decreases resistance and red light enhances it in certain combination of plant and pathogen, p. 21-23. Proc. COE-IGE Intl. Symp.: Plant and ultraviolet-B radiation-Effects of increasing ultraviolet-B radiation on ecosystem and resistance of plant to ultraviolet-B radiation. Tohoku Univ., Japan.

Honda, Y. and T. Yunoki. 1977. Control of sclerotiana disease of greenhouse eggplant and cucumber by inhibition of development of apothecia. Plant Dis. 61:1036-1040.

Hwang, B.K. and C.H. Kim. 1995. Phytophthora blight of pepper and its control in Korea. Plant Dis. 79:221-227.

Islam, S.Z., Y. Honda, and M. Sonhaji. 1998a. Phototropism of conidial germ tubes of Botrytis cinerea and its implication in plant infection processes. Plant Dis. 82:850-856.

Islam, S.Z., Y. Honda, and S. Arase. 1998b. Lightinduced resistance of broadbean against Botrytis cinerea. J. Phytopathol. 146:479-485.

Islam, S.Z., Y. Honda, and S. Arase. 1999. Some characteristics of red light-induced substance(s) against Botrytis cinerea produced in broadbean leaflets. J. Phytopathol. 147:65-70.

Kato, H., O. Kodama, and T. Akatsuka. 1994. Oryzalexin F, a diterpene phytoalexin from UVirradiated rice leaves. Phytochemistry 36:299301.

Kodama, O., J. Miyakawa, T. Akatsuka, and S. Kiyosawa. 1992. Sakuranetin, a flavanone phytoalexin from ultraviolet-irradiated rice leaves. Phytochemistry 31:3807-3809.

Kohmoto, K., H. Otani, M. Kodama, and S. Nishimura. 1989. Host recognition: Can accessibility to fungal invasion be induced by hostspecific toxins without necessitating necrotic cell death, p. 249-265. In: A. Graniti, R.D. Durbin, and A. Ballio (eds.). Phytotoxins and plant pathogenesis. NATO ASI Ser., Vol. H-27. Springer-Verlag, Berlin.

Kumagai, T. 1988. Photocontrol of fungal development. Photochem. Photobiol. 47:889-896.

Lee, B.K., B.S. Kim, S.W. Chang, and B.K. Hwang. 2001. Aggressiveness to pumpkin cultivars of isolates of Phytophthora capsici from pumpkin and pepper. Plant Dis. 85:497-500.

Matheron, M.E. and J.C. Matejka. 1995. Comparative activities of sodium tetrathiocarbonate and metalaxyl on Phytophthora capsici and root and crown rot on chile pepper. Plant Dis. 79:56-59.

Rahman, M.Z., N. Muroguchi, S. Arase, and Y. Honda. 2001. Effect of red light on the development of leaf spot disease in broadbean caused by Alternaria tenuissima. Proc. Annu. Mtg. Phytopathol. Soc. of Japan, Sendai.

Roberts, P.D., R.R. Urs, and R.J. McGovern. 2000. Age and varietial response of tomato to infection by Phytophthora capsici. Phytopathology 90:S65. (Abstr.)

Tan, K.K. 1978. Light-induced fungal development, p. 334-357. In: J.E. Smith and D.R. Berry (eds.). The filamentous fungi. Edward Arnold Ltd., London.

Thomas, M., S.L Ranson, and J.A. Richardson. 1973. Plant Physiol. 5th ed. J.W. Arrowsmith Ltd., Bristol, U.K.

Umezu, H., S.Z. Islam, and Y. Honda 1999. Red lightinduced resistance in some plants. Bul. Assoc. Plant Protect. Shimane Pref., Japan 24:55-57. 